\title{
ORIGINAL ARTICLE Modelling the health impact of environmentally sustainable dietary scenarios in the UK
}

\author{
P Scarborough $^{1}$, S Allender ${ }^{1,2}$, D Clarke ${ }^{1}$, K Wickramasinghe $^{1}$ and M Rayner ${ }^{1}$
}

\begin{abstract}
BACKGROUND/OBJECTIVES: Food is responsible for around one-fifth of all greenhouse gas (GHG) emissions from products consumed in the UK, the largest contributor of which is meat and dairy. The Committee on Climate Change have modelled the impact on GHG emissions of three dietary scenarios for food consumption in the UK. This paper models the impact of the three scenarios on mortality from cardiovascular disease and cancer.

SUBJECTS/METHODS: A previously published model (DIETRON) was used. The three scenarios were parameterised by fruit and vegetables, fibre, total fat, saturated fat, monounsaturated fatty acids, polyunsaturated fatty acids, cholesterol and salt using the 2008 Family Food Survey. A Monte Carlo simulation generated 95\% credible intervals.

RESULTS: Scenario 1 (50\% reduction in meat and dairy replaced by fruit, vegetables and cereals: $19 \%$ reduction in GHG emissions) resulted in 36910 (30 192 to 43 592) deaths delayed or averted per year. Scenario 2 (75\% reduction in cow and sheep meat replaced by pigs and poultry: 9\% reduction in GHG emissions) resulted in 1999 (1739 to 2389) deaths delayed or averted. Scenario 3 (50\% reduction in pigs and poultry replaced with fruit, vegetables and cereals: $3 \%$ reduction in GHG emissions) resulted in 9297 (7288 to 11301 ) deaths delayed or averted.

CONCLUSION: Modelled results suggest that public health and climate change dietary goals are in broad alignment with the largest results in both domains occurring when consumption of all meat and dairy products are reduced. Further work in real-life settings is needed to confirm these results.
\end{abstract}

European Journal of Clinical Nutrition (2012) 66, 710-715; doi:10.1038/ejcn.2012.34; published online 11 April 2012

Keywords: cardiovascular disease; sustainable diets; UK; cancer; meat; dairy

\section{INTRODUCTION}

The UK target for climate change is to reduce greenhouse gas (GHG) emissions to $80 \%$ below 1990 levels by $2050^{\text {(ref. } 1)}$ - a target that was made legally binding by the Climate Change Act $2008{ }^{2}$ Food and drink are estimated to be responsible for around a fifth of all emissions for products consumed in the UK. ${ }^{3}$ Within the food sector, livestock production is the most damaging process to the environment, both in terms of GHG emissions ${ }^{3-5}$ and other environmental burdens, including those owing to water and land use and the loss of biodiversity. ${ }^{6,7}$ Modelled impact assessments of potential improvements in the GHG efficiency of livestock production have concluded that technological improvements alone cannot be expected to reduce the environmental burden of livestock to levels required in order to meet climate change targets. $^{8-10}$ Reduction in the amount of livestock production (and therefore consumption) is also necessary. In their fourth carbon budget, the Committee on Climate Change (CCC)-established under the Climate Change Act to advise the UK Government on how it can meet its targets for GHG emissions-estimated the impact on GHG emissions and land use of three counterfactual dietary scenarios in which the amount and type of meat and dairy that is consumed in the UK is substantially altered, ${ }^{11}$ and concluded that 'there is a clear scope for emissions reduction owing to changed consumption, and net of any (increased) emissions owing to land-use change'. ${ }^{12}$

There is growing evidence of a link between high consumption of meat and poor health outcomes. ${ }^{13-20}$ This relationship may be because of high saturated fat content in animal products, high salt levels in processed meat or high consumption of meat limiting the consumption of fruit, vegetables and cereals, which have healthpromoting properties. Reviews of prospective cohort studies suggest that dairy products have a small protective effect on cardiovascular diseases, ${ }^{21}$ colorectal cancer $^{14}$ and possibly on weight gain. ${ }^{22}$ Recently, there have been calls for a reduction in meat consumption for the joint benefits of public health and environmental sustainability. ${ }^{23}$ The Director General of the World Health Organization, Margaret Chan, has written about the public health benefits of reduced consumption of animal products in developed countries, ${ }^{24}$ and the Swedish Government has amended dietary recommendations to state that 'To eat less meat, and to choose what you eat with care is... the most effective environmental choice you can make. From a health perspective, there is also no reason to eat as much meat as we do today'. ${ }^{25}$ This evidence is yet to convince the UK Government, whose advice on achieving an environmentally sustainable diet does not mention the impact of meat, and whose advice on achieving a healthy and

${ }^{1}$ British Heart Foundation Health Promotion Research Group, Department of Public Health, University of Oxford, Oxford, UK and ${ }^{2}$ Strategic Research Centre for Population Health, Deakin University, Geelong, Victoria, Australia. Correspondence: Dr P Scarborough British Heart Foundation Health Promotion Research Group, Department of Public Health, University of Oxford, Old Road Campus, Headington, Oxford OX3 7LF, UK.

E-mail: peter.scarborough@dph.ox.ac.uk

Contributors: PS, SA and MR designed the research; PS, DC and KW conducted the research; PS, DC and KW analysed data and performed statistical analyses; PS, SA wrote first draft of manuscript; PS, SA, DC, KW and MR commented on draft manuscripts and approved the final submission manuscript.

Received 4 November 2011; revised 9 March 2012; accepted 9 March 2012; published online 11 April 2012 
sustainable diet entirely consists of directing consumers to seasonably produced fruit and vegetables. ${ }^{26}$

This paper models the impact of the CCC dietary scenarios on the number of deaths from coronary heart disease, stroke and cancer in the UK, allowing for an assessment of what form of meat and dairy reduction would be most beneficial to public health and sustainability. Scenario 1 is a reduction in consumption of all meat and dairy products, replaced with fruit, vegetables and cereals. Scenario 2 is a shift from consumption of cow and sheep meat to pigs and poultry. Scenario 3 is a reduction in consumption of pigs and poultry, replaced with fruit, vegetables and cereals. The environmental impacts of these three scenarios have previously been quantified. ${ }^{12}$ The results in this paper answer three questions: What scenario of meat and dairy reduction would have the biggest impact on chronic disease mortality? What changes in the diet are the main drivers of this impact? Are environmentally sustainable dietary goals in alignment with public health goals?

\section{MATERIALS AND METHODS}

The CCC dietary scenarios are described in Table 1, using comparison with the UK diet in 2005 as baseline (for example, scenario 1 has meat consumption at $36 \%$ of the consumption of meat in 2005). The substitution between food categories that is explicit in the scenarios was based on the assumption that a constant food energy supply would require an increase in fruit, vegetables and cereals to balance a reduction in meat and dairy consumption, and the level of substitution was based on food energy at the commodity level from UK food balance sheets. Scenario $1(50 \%$ reduction in meat and dairy) was subjected to expert opinion, which suggested that the scenario was viable from a nutritional perspective. ${ }^{11}$ Scenario 1 has the largest environmental impact, resulting in a 19\% reduction in GHG emissions and a $42 \%$ reduction in land use for foods consumed in the UK.

The DIETRON mode ${ }^{27}$ was used to estimate the annual number of deaths from coronary heart disease (CHD), stroke or cancers of the mouth, larynx and pharynx, oesophagus, stomach and lung that would be delayed or averted in the UK under each dietary scenario. A full description of the development, parameterisation and assumptions supporting the DIETRON model is available in an appendix of a previously published open-access article. $^{28}$ Briefly, the DIETRON model uses age- and sex-specific estimates of relative risk drawn from meta-analyses of trials, cohort studies and casecontrol studies, to estimate the impact on chronic disease mortality of counterfactual population dietary scenarios. The dietary input data for the model are consumption of: total energy (kcal/day); fruit ( $\mathrm{g} / \mathrm{day})$; vegetables ( $\mathrm{g} /$ day); fibre $(\mathrm{g} /$ day); total fat (\% total energy); monounsaturated fatty acids (\% total energy); polyunsaturated fatty acids ( $\%$ total energy); saturated fatty acids ( $\%$ total energy); trans fats ( $\%$ total energy); dietary cholesterol (\% total energy); salt ( $\mathrm{g} /$ day). The model combines risk estimates multiplicatively, and the conceptual framework has been designed to minimise the chance of double counting. The model can estimate the combined impact of changing a range of dietary factors simultaneously, and also estimate the impact of changing each dietary factor individually. This allows for an assessment of the 'overlap' in each counterfactual scenario: the impact of changing each dietary factor simultaneously is less than the sum of changing each factor individually.

Nutritional quality of baseline diets and counterfactual scenarios The baseline diet (that is, measures of the average nutritional quality of the current diet in the UK) was taken from the 2008 Family Food Survey (FFS), which collects data on food purchases from a representative sample of UK households. ${ }^{29}$ To construct the counterfactual dietary scenarios, each of the 256 food categories identified in the FFS were classified as one of the categories identified in the scenarios (for example, the FFS category 'processed cheese' was assigned to the 'Milk and eggs' CCC category). The proportional increase or decrease in consumption of each of the CCC food categories was then applied in accordance with the scenarios, under the assumption that the pattern of food consumption within each category would be the same (for example, that reductions in dairy consumption would be achieved by equal reductions of skimmed milk, whole milk, butter etc). Examples of categorisation include: fish (other foods); cakes and pastries (cereals/ potatoes); pizzas (other foods).

All counterfactual diets were rescaled so that the total energy intake was the same as for the baseline diets. It was not possible to obtain data on trans fats levels for either the modelled scenarios or the baseline diets, because trans fats are not recorded in the FFS, so throughout, we have

Table 1. CCC dietary scenarios from the fourth carbon budget

CCC Scenario Dietary definition Estimated environmental impact

Food consumption (\% of 2005 levels)

Scenario 1:

'A 50\% reduction in livestock product supply

balanced by increases in plant commodities. ${ }^{12}$

Scenario 2:

'A shift from red (for example, beef and sheep meat) to white (pigs and poultry meat), with no overall reduction in livestock consumption. ${ }^{12}$

Scenario 3:

'A 50\% reduction in white meat supply balanced by increases in plant commodities. ${ }^{12}$

$\begin{array}{ll}\text { Milk and eggs } & 60 \\ \text { Meat } & 36 \\ \text { Sugar } & 70 \\ \text { Vegetables/fruits } & 160 \\ \text { Cereals/potatoes } & 133 \\ \text { Vegetable oils (not palm) }^{\text {Other groups }}{ }^{\mathrm{a}} & 133 \\ \text { Or }^{2} & 100\end{array}$

Milk and eggs

Cow and sheep

Pig and poultry

Sugar

Vegetables/ fruit

Cereals/potatoes

Vegetable oils (not palm)

Other groups ${ }^{a}$

Milk and eggs

Cow and sheep

Pig and poultry

Sugar

Vegetables/fruit

Cereals/potatoes

Vegetable oils (not palm)

Other groups ${ }^{a}$

160

133

100

100

100

100

100

100

100

100

50

90

110

110

110

100
$19 \%$ reduction in UK agriculture GHG emissions, and $42 \%$ reduction in land use compared with 2008 baseline $^{\text {b }}$

$1009 \%$ reduction in UK agriculture GHG emissions,

25 and 39\% reduction in land use compared with 2008 145 baseline ${ }^{\mathrm{b}}$ 
assumed that trans fat intake would remain constant at $1.6 \mathrm{~g} / \mathrm{day}$, the average level of consumption in the UK in 2008/09. ${ }^{30}$

Age- and sex-specific number of deaths from CHD, stroke and cancer for the whole of the UK in 2008 were provided by the Office for National Statistics and General Register Offices of Scotland and Northern Ireland.

\section{Comparison with data from the National Diet and Nutrition Survey} (NDNS)

Estimates of dietary quality derived from food purchase data are limited, as they do not take account of wastage within the household. Therefore, the baseline diet used in the analyses was compared with the diet of the adult population (aged 19-64) of Great Britain derived from the NDNS in 2000/01. ${ }^{31}$ The NDNS uses weighed 7-day food diary data to assess dietary quality of a representative sample of participants. After excluding participants who reported implausible energy consumption $(<1000 \mathrm{kcal} /$ day $(n=104)$ or $>3000 \mathrm{kcal} /$ day $(n=47))$, the average dietary quality of the remaining 1573 participants was calculated. Additionally, the NDNS was used to assess the plausibility of the CCC scenarios, by identifying a subsample of the NDNS that currently achieves similar meat and dairy consumption levels as described in CCC scenario 1, and assessing the consumption of fruit, vegetables and cereals in this subsample.

\section{Uncertainty analysis}

A Monte Carlo simulation was performed to estimate 95\% credible intervals around the results. These credible intervals are based on the 2.5th and 97.5th percentiles of results generated from 5000 iterations of the DIETRON models, where the estimates of relative risks used to parameterise the model were allowed to vary stochastically according to the distributions reported in the literature.

\section{RESULTS}

Table 2 shows the nutritional quality of the baseline diets and counterfactual scenarios. All of the scenarios showed an increase in fruit and vegetable consumption-increases of $63 \%$ for scenario 1 $1 \%$ for scenario 2 and $13 \%$ for scenario 3 . The counterfactual scenarios also showed a decrease in saturated fat and salt consumption, although these decreases were small. Micronutrient intake generally seems similar in the counterfactual scenarios, with the exception of a large drop in vitamin B12 in scenario 1.

In 2008, there were 226743 deaths from CHD, stroke or dietrelated cancers in the UK. The dietary scenario that would have the largest impact on deaths from CHD, stroke and cancer was scenario 1, which would result in 36910 deaths delayed or averted (95\% credible intervals: 30192 to 43592 ). This was followed by scenario 3 with 9297 (7288 to 11301) deaths delayed or averted, then scenario 2 with 1999 (1739 to 2389) deaths delayed or averted. For each of the scenarios, the biggest impact was on deaths from CHD (Figure 1). Full results described by condition, age and sex are presented in the Supplementary Table.

For scenario 1, the largest contributor to deaths delayed or averted was increased fruit and vegetable consumption, which accounted for 27866 (21 254 to 33878 ) deaths delayed or averted. In contrast, reductions in salt consumption and changes in the fatty acid composition of the diet would have much smaller influences. A similar pattern for deaths delayed or averted and changes in nutrient intakes was predicted for scenario 3 , where pigs and poultry were replaced by fruits, vegetables and cereals. The only scenario that did not involve a large increase in fruit and vegetable consumption was scenario 2 (a switch from cow and sheep meat to pigs and poultry). This resulted in a modest number of deaths delayed or averted, mostly from the change in fatty acid composition (983 (763 to 1312) deaths delayed or averted).

The baseline diet from the FFS (used in the modelling) was similar to that from the NDNS (Table 3 ) in most regards, with slightly higher overall consumption recorded in the FFS than in the NDNS. However, the FFS suggested a substantially higher fruit and vegetable intake $(290 \mathrm{~g} /$ day $)$ than measured in the NDNS ( $203 \mathrm{~g} /$ day). The subsample of the NDNS that achieved similar
Table 2. Nutritional quality of baseline and modelled diets

\begin{tabular}{|lcccc|}
\hline & $\begin{array}{r}\text { Baseline- } \\
\text { FFS 2008 }\end{array}$ & $\begin{array}{r}\text { CCC } \\
\text { scenario 1 }\end{array}$ & $\begin{array}{r}\text { CCC } \\
\text { scenario 2 }\end{array}$ & $\begin{array}{r}\text { CCC } \\
\text { scenario 3 }\end{array}$ \\
\hline Energy (kcal/day) & 1966 & 1966 & 1966 & 1966 \\
Total fat (g/day) & 86.1 & 81.5 & 83.7 & 86.1 \\
SAFAs (g/day) & 33.8 & 29.7 & 32.5 & 33.5 \\
MUFAs (g/day) & 31.5 & 29.7 & 30.5 & 31.3 \\
PUFAs (g/day) & 15.2 & 16.7 & 15.3 & 15.7 \\
Cholesterol (mg/day) & 227 & 153 & 220 & 211 \\
Fibre (g/day) & 13.5 & 17.7 & 13.5 & 14.8 \\
Salt (g/day) & 6.2 & 6.0 & 6.1 & 6.1 \\
Fruit and & 290 & 473 & 294 & 328 \\
vegetables (g/day) & & & & \\
Iron (mg/day) & 10.5 & 11.8 & 10.0 & 11.1 \\
Calcium (mg/day) & 904 & 854 & 908 & 943 \\
Zinc (mg/day) & 8.3 & 7.4 & 7.6 & 8.4 \\
Riboflavin (mg/day) & 1.7 & 1.5 & 1.7 & 1.8 \\
Vitamin A ( $\mu$ g/day) & 799 & 727 & 731 & 812 \\
Vitamin D ( $\mu$ g/day) & 2.7 & 2.3 & 2.6 & 2.6 \\
Vitamin B12 ( $\mu$ g/day) & 5.8 & 3.9 & 5.2 & 5.7 \\
\hline Abbrevitions: cCC, Comm & & &
\end{tabular}

Abbreviations: CCC, Committee on Climate Change; FFS, Family Food Survey; MUFAs, monounsaturated fatty acids; PUFAs, polyunsaturated fatty

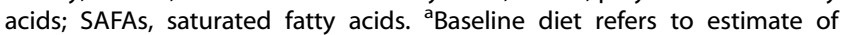
current UK population average diet from the 2008 Family Food Survey.

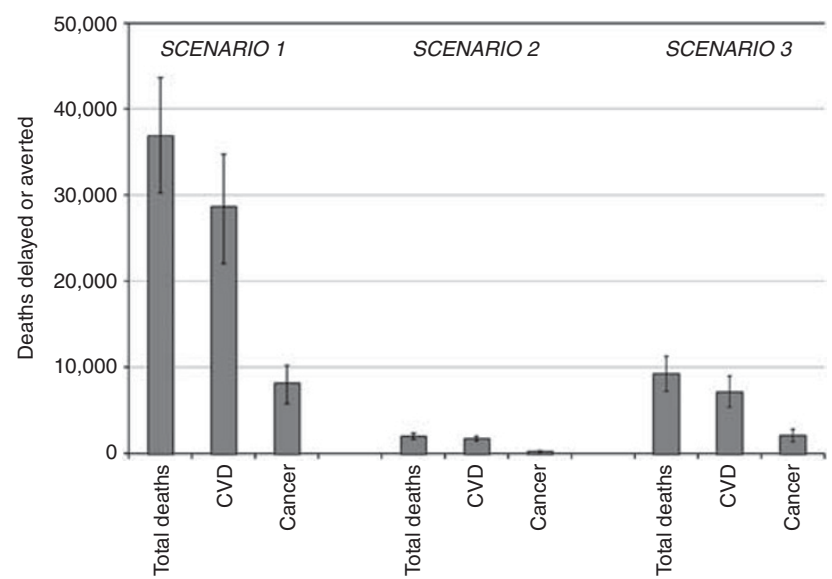

Figure 1. Number of deaths (total and cause-specific) delayed or averted per year by dietary scenarios compared with baseline diets.

levels of meat and dairy consumption as required for scenario 1 consumed $81 \%$ more fruit and vegetables and $18 \%$ more cereals and potatoes than the full NDNS sample. This suggests that individuals who currently consume meat and dairy at a level described in scenario 1 do compensate by consuming greater quantities of fruit, vegetables and cereals (Table 4).

\section{DISCUSSION}

Although it has previously been assumed that public health and environmental sustainability goals for the food system may be similar, ${ }^{5,23,32}$ these results are the first to test that assumption by quantifying the impact of reduced meat scenarios on both GHG emissions and health outcomes robustly. The results reveal synergies between the two domains: for each of the CCC dietary scenarios, the DIETRON model predicted a positive impact on cardiovascular and cancer mortalities. But the results also reveal tensions: a switch from consumption of cows and sheep to pigs and poultry would have a substantial impact on GHG emissions associated with UK food consumption $(9 \%$ reduction in 
Table 3. Comparison of diets of population of the UK, as measured by the FFS 2008 and NDNS 2000/01

\begin{tabular}{lcc}
\hline & $F F S^{a}$ & $N D N S^{b}$ \\
\hline Energy (kcal/day) & 1966 & 1806 \\
Total fat (\% energy) & 39.4 & 36.3 \\
SAFAs (\% energy) & 15.5 & 13.8 \\
MUFAs (\% energy) & 14.4 & 12.0 \\
PUFAs (\% energy) & 7.0 & 6.4 \\
Cholesterol (mg/day) & 227 & 255 \\
Fibre (g/day) & 13.5 & 13.9 \\
Salt (g/day) & 6.2 & 6.9 \\
Fruit and vegetables (g/day) & 290 & 203 \\
\hline
\end{tabular}

Abbreviations: FFS, Family Food Survey; MUFAs, monounsaturated fatty acids; NDNS, National Diet and Nutrition Survey; PUFAs, polyunsaturated fatty acids; SAFAs, saturated fatty acids. ${ }^{a}$ Estimates derived from food purchase data and are not adjusted for wastage in the home. Survey population-adults and children of all ages, UK, Survey year-2008. ${ }^{b}$ Estimates derived from 7-day-weighed food diaries. Participants reporting consumption outside the range of $1000-3000 \mathrm{kcal} /$ day removed. Estimates based on 1573 participants. Survey population-adults aged 19-64, Great Britain. Survey year-2000/01. 'Estimated from salt levels in purchased or consumed foods and does not include salt added during cooking or at the table.

Table 4. Comparison of modelled food production in CCC scenario 1 (low meat and dairy consumption) with food consumption by low meat and dairy consumers from the National Diet and Nutrition Survey 2000/01

\begin{tabular}{|c|c|c|}
\hline & CCC scenario 1 & $\begin{array}{l}\text { Low meat and } \\
\text { dairy consumers }\end{array}$ \\
\hline & $\begin{array}{l}\text { Comparison with } \\
2005 \text { production } \\
\text { levels (\%) }\end{array}$ & $\begin{array}{c}\text { Comparison } \\
\text { with 2000/01 } \\
\text { consumption levels (\%) }\end{array}$ \\
\hline Milk and eggs & 60 & 64 \\
\hline Total meat & 36 & 35 \\
\hline Sugar & 70 & 116 \\
\hline Fruit and vegetables & 160 & 181 \\
\hline Cereals and potatoes & 133 & 118 \\
\hline $\begin{array}{l}\text { Vegetable oils } \\
\text { (not palm) }\end{array}$ & 133 & 146 \\
\hline Other & 100 & 113 \\
\hline \multicolumn{3}{|c|}{ 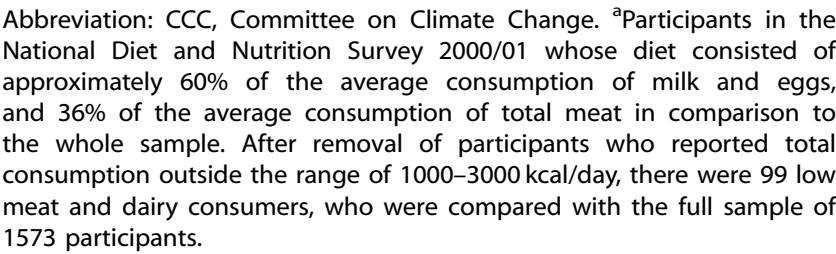 } \\
\hline
\end{tabular}

comparison with 2005), but very little impact on chronic disease deaths. By assessing these synergies and tensions, we are able to present evidence-based advice about dietary recommendations aimed at reducing both environmental impact and deaths from chronic disease. According to these results, such recommendations should encourage reduced consumption of all meat and dairy products and substitution with fruit, vegetables and cereals. However, further work should be aimed at verifying the health benefits of reducing meat and dairy consumption in real-life settings, and addressing the effect of reduced meat and dairy consumption on micronutrient consumption in vulnerable subgroups of the population.

The dietary scenarios modelled in this paper were designed by the CCC to assess the impact of changes in food consumption in the UK on GHG emissions and land use. The scenarios were not designed to be targets or goals for future consumption. Scenario 1 (the most effective scenario for both public health and environmental sustainability) represents a substantial change from the current pattern of consumption in the UK, and if it were adopted as a target, then it would be a considerable challenge for most consumers and indeed producers of food. However, the comparison with diets achieved in the NDNS presented in Table 3 suggest that people who consume a considerably lower amount of meat and dairy products than the UK average do compensate by eating larger amounts of fruits, vegetables and cereals in quantities comparable to those outlined in scenario 1. Therefore, although moving the population to this diet may be difficult, there are already individuals within the UK (around $6 \%$ of the NDNS sample) consuming a similar, achievable diet.

There have been at least two other assessments of the health impact of achieving environmentally sustainable diets reported in the literature. A series of dietary scenarios designed to feed an enlarged world population in 2050 equitably ${ }^{33}$ - which also would require considerable reductions in meat and dairy consumptionwere subjected to similar modelling techniques, and similar results were found, namely that a substantial reduction in meat and dairy consumption in the UK coupled with increases in fruit, vegetable and cereal consumption would produce considerable reductions in cardiovascular and cancer mortalities. ${ }^{34}$ Friel et al. ${ }^{32}$ estimated that a $30 \%$ reduction in consumption of meat and dairy would result in a reduction of 18000 premature deaths due to CHD. Friel et al. $^{32}$ estimated that the $30 \%$ reduction in meat and dairy would result in a $30 \%$ reduction in saturated fat and dietary cholesterol that would be replaced by polyunsaturated fatty acids, which would reduce CHD mortality via reductions in blood cholesterol, whereas our analysis suggests that the most important factor would be increased fruit and vegetable consumption. Our results initially appear to be in conflict with the epidemiological evidence of the impact of meat consumption on cardiovascular diseaserecent meta-analyses suggest only modest associations between total meat intake and CHD, diabetes and stroke. ${ }^{20}$ However, the aim of the meta-analyses was to find the independent impact of meat consumption - that is, the effect on cardiovascular disease of changing meat consumption but keeping other dietary factors constant. Our analyses do not keep other dietary factors constant-reductions in meat are accompanied by big increases in fruit, vegetables and cereals. Table 5 demonstrates that the health impact associated with reductions in saturated fat and salt intake (due primarily to reductions in meat consumption) is much smaller.

The DIETRON model used for this analysis produces robust estimates of the health impact of changes in dietary quality, and is the most comprehensive model currently available for assessing the impact of dietary change on chronic disease mortality. The Monte Carlo analysis allows for an estimation of the uncertainty in the results that is a result of uncertainty in the strength of the association between dietary factors and health outcomes, but this is not the only source of uncertainty in the modelling processother sources include uncertainty regarding baseline nutritional quality of the UK diet and uncertainty associated with assuming log-linear relationships between exposures and outcomes-so the degree of uncertainty in the results is underestimated. Results of modelling can only provide a hypothetical estimate of the change in mortality that would result with sustained consumption of a different diet with no other lifestyle changes. The implied causality in the results of this paper (that is, reducing meat and dairy consumption in the UK would cause reduced cardiovascular disease and cancer mortality rates) should be questioned. For example, the model is parameterised by meta-analyses of observational studies, and it is therefore not possible to rule out the possibility of residual confounding. Additionally, it is not clear whether the diet of the population would adjust to reduced meat 
Table 5. Total deaths delayed or averted per year by nutritional changes in the dietary scenarios compared with baseline diets

\begin{tabular}{|lrr|}
\hline & $\begin{array}{c}\text { Deaths averted } \\
\text { or delayed }\end{array}$ & \multicolumn{1}{c|}{$\begin{array}{l}\text { 95\% Credible } \\
\text { intervals }\end{array}$} \\
\hline Scenario 1 & & \\
$\quad$ Fruits and vegetables & 27866 & $21254-33878$ \\
Fibre & 7470 & $3275-11423$ \\
Fats & 2847 & $2351-3653$ \\
Salt & 658 & $539-776$ \\
All dietary components & 36910 & $30192-43592$ \\
& & \\
Scenario 2 & & $526-871$ \\
$\quad$ Fruits and vegetables & 694 & $0-0$ \\
Fibre & 0 & $763-1312$ \\
Fats & 983 & $271-389$ \\
Salt & 330 & $1739-2389$ \\
All dietary components & 1999 & \\
Scenario 3 & & $4882-7998$ \\
$\quad$ Fruits and vegetables & 6408 & $241-367$ \\
Fibre & 2383 & $271-389$ \\
Fats & 289 & $7288-11301$ \\
Salt & 330 & \\
All dietary components & 9297 & \\
\hline
\end{tabular}

Note: estimates for each dietary component are the change that would result if only the individual component changed in the counterfactual scenario. The 'all dietary components' rows are less than the sums of the individual dietary components as double counting has been accounted for in the modelling process.

and dairy consumption by increasing fruit, vegetable and cereal consumption as suggested by the dietary scenarios. Similarly, the effects of reduced meat and dairy production on GHG emissions relies on the assumption that meat and dairy products will be replaced in the diet by fruit, vegetables and cereals.

A particular limitation to this analysis is that it does not take account of the health effects of nutrient deficiencies that may result from a reduction in meat and dairy consumption. An indepth report on the micro-nutritional challenges of reducing meat and dairy consumption in the UK suggested that deficiency in zinc, calcium, iodine, vitamin B12 and riboflavin are likely to increase, unless met with public health advice on alternative dietary sources of these nutrients. ${ }^{35}$ The modelled dietary scenarios presented in Table 2 suggest that levels of iron, calcium, zinc, riboflavin, vitamin A and vitamin D in the UK will not be affected severely, but consumption of vitamin B12 may be. These results are limited (for example, it is not clear to what degree the substituted micronutrients are bioavailable; levels of consumption in vulnerable subpopulations have not been considered) and the issue requires further specialised investigation. In our modelled scenarios, all types of meat and dairy products were equally likely to be replaced. If, in contrast, less healthy versions of meat and dairy products (for example, full-fat milk) were more likely to be removed from the diet than healthier versions, then the results will underestimate the health impact of the dietary scenarios. To our knowledge, it is not known whether this is a more likely situation, so we chose to model the more conservative approach.

The modelling presented here relied on a survey of food purchase data for input data on the current UK diet. Although our comparison with NDNS food and nutrient intake data (Table 3) suggests that the baseline diet estimates are reasonably valid, it does suggest that current UK fruit and vegetable consumption may have been overestimated. This is likely to be the case, as household wastage of fruit and vegetables is higher than that for other food categories. ${ }^{36}$ This may have resulted in some overestimation of the health impact of achieving the dietary scenarios. However, more recent data from the first 2 years of rolling data collection for the NDNS shows a higher level of fruit and vegetable consumption in the UK, partially because of inclusion of fruit and vegetables in composite dishes within its calculation. In 2008/10, the mean consumption for adults aged 19-64 years was $288 \mathrm{~g} /$ day. ${ }^{37}$ The DIETRON model assumes that past dietary consumption patterns have no effect on risk of disease, which is clearly an oversimplification likely to result in some overestimation of the benefits of dietary change. But there are two reasons why the results presented here are likely to be an underestimate of the true impact of reduced meat and dairy consumption on CHD, stroke and cancer mortalities: first, we did not include in the model the association between red meat/processed meat consumption and colorectal cancer ${ }^{14}$ because of concerns of double counting; second, we assumed there would be no change in total energy intake (and hence body weight) associated with lower meat and dairy intake, but meat and dairy products are energy-dense foods and it has been suggested that high meat consumption is associated with raised $\mathrm{BMI}^{38}$

This paper is a contribution to the growing literature that considers the twin challenges of public health and climate change. $^{39}$ Further work should also consider the impact of changes in diet on macro-economics, both of developed and developing countries. Recent work has suggested that reductions in the consumption of meat and dairy products in the UK would have a limited impact on the UK economy, but a considerable negative impact on the economy of Brazil. ${ }^{40}$ There may be similar negative impacts to the economies of developing countries that rely heavily on the production of livestock, which currently supports almost a billion of the world's poorest people. ${ }^{41}$ Future work should also explore interventions that could potentially lead to a reduction in meat and dairy consumption in the developed world. It has been suggested that removal of subsidies for livestock production would be helpful ${ }^{42}$ and that market-based initiatives (pricing of externalities-for example, carbon and other GHGs - via carbon taxes or cap-and-trade schemes) would be the most effective and efficient system. ${ }^{43}$

\section{CONFLICT OF INTEREST}

The authors declare no conflict of interest.

\section{ACKNOWLEDGEMENTS}

We acknowledge the support of Tim Key and Paul Appleby for providing data for the analyses, and Kavita Srinivasan and Donal Murphy-Bokern for advice regarding the dietary scenarios. This work was funded by the British Heart Foundation.

\section{REFERENCES}

1 Committee on Climate Change (CCC) Building a low-carbon economy - the UK's contribution to tackling climate change. CCC: London, 2008.

2 UK Government. Climate Change Act 2008. Internet: http://www.legislation.gov. uk/ukpga/2008/27 (accessed 24 November 2010).

3 Garnett T. Cooking up a Storm. Food, Greenhouse Gas Emissions and our Changing Climate. Food Climate Research Network: Guildford, 2008

4 Steinfeld H, Gerber P, Wassenaar T, Castel V, Rosales M, de Haan C. Livestock's Long Shadow. Food and Agriculture Organization: Rome, 2006.

5 Sustainable Development Commission Setting the Table. Advice to Government on Priority Elements of Sustainable Diets. Sustainable Development Commission: London, 2009.

6 Marlow H, Hayes W, Soret S, Carter R, Schwab E, Sabate J. Diet and the environment: does what you eat matter? Am J of Clin Nutr 2009; 89S: 1699S-1703S.

7 Foster C, Green K, Bleda M, Dewick P, Evans B, Flynn A et al. Environmental Impacts of Food Production and Consumption: A Report to the Department of the Environment, Food and Rural Affairs. DEFRA: London, 2006.

8 Wirsenius S, Hedenus F. Policy strategies for a sustainable food system: options for protecting the climate. In: D'Silva J, Webster J (eds) The Meat Crisis. Developing more Sustainable Production and Consumption. Earthscan: London, pp 237-253, 2010. 
9 Weidema B, Wesnaess M, Hermanses J, Kristensen $T$, Halberg N Environmental Improvement Potentials of Meat and Dairy Products. European Commission Joint Research Centre, Institute for Prospective Technological Studies: Seville, 2008.

10 McMichael A, Powles J, Butler C, Food Uauy R. Livestock production, energy, climate change, and health. Lancet 2007; 370: 1253-1263.

11 Audsley E, Chatterton J, Graves A, Morris J, Murphy-Bokern D, Pearn K et al. Land and greenhouse gases. The Effect of Changes in UK Food Consumption on Land Requirements and Greenhouse Gas Emissions. Committee on Climate Change: London, 2010.

12 Committee on Climate Change (CCC) The Fourth Carbon Budget. Reducing Emissions Through the 2020s. CCC: London, 2010.

13 Sinha R, Cross A, Graubard B, Leitzmann M, Schatzkin A. Meat intake and mortality. Arch of Intern Med 2009; 169: 562-571.

14 American Institute for Cancer Research (AICR) \& World Cancer Research Fund Food, Nutrition, Physical Activity and the Prevention of Cancer: A Global Perspective. AICR: Washington DC, 2007.

15 Tzoulaki I, Brown I, Chan Q, van Horn L, Ueshima H, Zhao L et al. For The International Collaborative Research Group on Macro-/Micronutrients and Blood Pressure. Relation of iron and red meat intake to blood pressure: cross sectional epidemiological study. BMJ 2008; 337: a258.

16 Thorogood M, Mann J, Appleby P, McPherson K. Risk of death from cancer and ischaemic heart disease in meat and non-meat eaters. BMJ 1994; 308: 1667-1669.

17 Key T, Fraser G, Thorogood M, Appleby P, Beral V, Reeves G et al. Mortality in vegetarians and nonvegetarians: detailed findings from a collaborative analysis of 5 prospective studies. Am J Clin Nutr 1999; 70S: 516S-524S.

18 Larsson S, Virtamo J, Wolk A. Red meat consumption and risk of stroke in Swedish men. Am J Clin Nutr 2011; 94: 417-421.

19 Pan A, Sun Q, Bernstein A, Schulze M, Manson J, Willett W et al. Red meat consumption and risk of type 2 diabetes: 3 cohorts of US adults and an updated meta-analysis. Am J Clin Nutr 2011; 94: 1088-1096.

20 Micha R, Wallace S, Mozaffarian D. Red and processed meat consumption and risk of incident coronary heart disease, stroke and diabetes mellitus. A systematic review and meta-analysis. Circulation 2010; 121: 2271-2283.

21 Elwood P, Pickering J, Givens D, Gallacher J. The consumption of milk and dairy foods and the incidence of vascular disease and diabetes: an overview of the evidence. Lipids 2010; 45: 925-939.

22 Louie J, Flood V, Hector D, Rangan A, Gill T. Dairy consumption and overweight and obesity: a systematic review of prospective cohort studies. Obes Rev 2011; 12: e582-e592.

23 Powles J. Commentary: why diets need to change to avert harm from global warming. Int J Epidemiol 2009; 38: 1141-1142.

24 Chan M. Cutting carbon, improving health. Lancet 2009; 374: 1870-1871.

25 National Food Administration The National Food Administration's Environmentally Effective Food Choices. National Food Administration: Uppsala, Sweden, 2009.

26 DirectGov. Food and drink: greener choices. Internet: http://www.direct.gov.uk/ en/Environmentandgreenerliving/Greenerhomeandgarden/Greenershopping/ DG_064434 (accessed September 2011).
27 Scarborough P, Nnoaham K, Clarke D, Rayner M, Capewell S. Modelling the impact of a healthy diet on cardiovascular disease and cancer mortality. J Epidemiol Community Health 2010; doi:10.1136/jech.2010.114520.

28 Scarborough P, Morgan R, Webster P, Rayner M. Differences in coronary heart disease, stroke and cancer mortality rates between England, Scotland, Wales and Northern Ireland: the role of diet and nutrition. BMJ Open 2011; 1: e000263.

29 Office for National Statistics Family Food in 2008. The Stationery Office: London, 2010.

30 Bates B, Lennox A, Swan G. National Diet and Nutrition Survey. Headline Results from Year 1 of the Rolling Programme (2008/2009). Food Standards Agency: London, 2010.

31 Henderson L, Gregory J, Swan G. National Diet and Nutrition Survey: adults aged 19 to 64 years. Office for National Statistics: London, 2002.

32 Friel S, Dangour A, Garnett T, Lock K, Chalabi Z, Roberts I et al. Public health benefits of strategies to reduce greenhouse-gas emissions: food and agriculture. Lancet 2009; 374: 2016-2025.

33 Erb K-H, Haberl H, Kraussmann F, Lauk C, Plutzar C, Steinberger J et al. Eating the Planet: Feeding and Fuelling the World sustainably, Fairly and Humanely A Scoping Study. Compassion in World Farming and Friends of the Earth: London, 2010.

34 Friends of the Earth Healthy Planet Eating. How Lower Meat Diets Can Save Lives and the Planet. Friends of the Earth: London, 2010.

35 Millward DJ, Garnett T. Food and the planet: nutritional dilemmas of greenhouse gas emission reductions through reduced intakes of meat and dairy foods Proc Nutr Soc 2010; 69: 103-118.

36 Quested T, Johnson H. Household Food and Drink Waste in the UK. WRAP: London, 2009.

37 Bates B, Lennox A, Bates C, Swan G. National Diet and Nutrition Survey. Headline Results from Years 1 and 2 (Combined) of the Rolling Programme (2008/20092009/10). Department of Health: London, 2011.

38 Wang $\mathrm{Y}$, Beydoun M. Meat consumption is associated with obesity and central obesity among US adults. Int $J$ Obes 2009; 33: 621-628.

39 Haines A, McMichael A, Smith K, Roberts I, Woodcock J, Markandya A et al. Public health benefits of strategies to reduce greenhouse-gas emissions: overview and implications for policy makers. Lancet 2009; 374: 2104-2114.

40 Lock K, Smith R, Dangour A, Keogh-Brown M, Pigatto G, Hawkes C et al. Health, agricultural, and economic effects of adoption of healthy diet recommendations. Lancet 2010; 376: 1699-1709.

41 Pretty J, Sutherland W, Ashby J, Auburn J, Baulcombe D, Bell M et al. The top 100 questions of importance to the future of global agriculture. Int J Agric Sustainability 2010; 8: 219-236.

42 Popkin B. Reducing meat consumption has multiple benefits for the World's health. Arch Intern Med 2009; 169: 543-545.

43 Kasterine A, Vanzetti D. The effectiveness, Efficiency and Equity of Market-Based and Voluntary Measures to Mitigate Greenhouse Gas Emissions from the Agri-Food Sector. United Nations: New York, 2010. NonCommercial-Share Alike 3.0 Unported License. To view a copy of this license, visit http://creativecommons.org/licenses/by-nc-sa/3.0/

Supplementary Information accompanies the paper on European Journal of Clinical Nutrition website (http://www.nature.com/ejcn) 